\title{
Nasal Analysis of Classic Animated Movie Villains versus Hero Counterparts
}

\author{
Meredith A. Allen, BS ${ }^{10}$ \\ Giancarlo Zuliani, $\mathrm{MD}^{2,4}$ \\ ${ }^{1}$ Department of Otolaryngology, Oakland University William \\ Beaumont School of Medicine, Rochester, Michigan \\ ${ }^{2}$ Department of Otolaryngology - Head and Neck Surgery, \\ Wayne State University School of Medicine, Detroit, Michigan \\ ${ }^{3}$ Department of Otolaryngology, University of Tennessee, \\ Memphis, Tennessee \\ ${ }^{4}$ Department of Otolaryngology - Head and Neck Surgery, \\ Zuliani Facial Aesthetics, Bloomfield Hills, Michigan
}

Facial Plast Surg 2021;37:348-353.

\begin{abstract}
Address for correspondence Meredith A. Allen, BS, Department of Otolaryngology, Oakland University William Beaumont School of Medicine-Rochester, MI 48309 (e-mail: meredithallen@oakland.edu).
\end{abstract}

\begin{abstract}
Keywords

- nasal analysis

- nasal characteristics

- animated characters

- character design

Opposing facial features between animated villains and heroes have historically been used to demonstrate contrasting morality between characters, and this could have an impact on how humans view someone as good or evil in everyday life. Studies have been done investigating classic dermatologic features of villainous characters. This principle can be applied to nasal features as well. A search for "top animated characters" was performed. Characters were chosen from American Film Institute's “The Top Tens," Rolling Stone's "25 Best Pixar Movie Characters," and Screenrant's "The 30 Best Animated Movie Characters of All Time." Twenty villains and twenty hero counterparts from respective films were chosen. Classic nasal features were analyzed. Twenty villains ( 14 male, 6 female) and 20 heroes ( 12 male, 8 female) were analyzed. Sixteen villains (80\%) had greater than normal nasal frontal angle versus 18 heroes (90\%). Thirteen villains (65\%) had an acute nasolabial angle versus two heroes (10\%). Two villains (10\%) had excess columellar show versus seven heroes (35\%). Seven villains (35\%) and one hero (5\%) had a dorsal hump. Twelve villains (60\%) had an overprojected chin versus three heroes (15\%). Villains in pre-2000s films more frequently had a dorsal hump, overprojected chin, ptotic tip, pollybeak deformity, and bulbous tip. Heroes in pre-2000s films more frequently had an overrotated tip. Villains and heroes commonly have a greater than normal nasofrontal angle. Villains more commonly have an acute nasolabial angle, underrotated tip, overprojected chin, dorsal hump, and pollybeak deformity. Heroes more commonly have a large nasolabial angle and overrotated tip. Further research in conjunction with psychologists is required to obtain concrete data on how this affects whether an individual in real life is seen as good or evil, and the impact this has on interactions in society, including in the medical field.
\end{abstract}

Filmmakers and illustrators have historically used facial features to differentiate animated villains from their hero counterparts to persuade the viewer to feel a certain way about a character, and this may subconsciously affect how humans view each other in the real world. Studies have been performed investigating classic dermatologic features of villainous characters such as facial scarring, alopecia, deep rhytids, periorbital hyperpigmentation, rhinophyma, verruca vulgaris, extensive tattoos, published online September 17, 2020
Issue Theme Facial Plastic Surgery Original Research; Guest Editors: Anthony P. Sclafani, MD, MBA, FACS, and Alwyn D'Souza, MBBS, FRCS Eng, FRCS (ORL-HNS) (c) 2020. Thieme. All rights reserved. Thieme Medical Publishers, Inc., 333 Seventh Avenue, 18th Floor, New York, NY 10001, USA
DOI https://doi.org/ $10.1055 / \mathrm{s}-0040-1716885$. ISSN 0736-6825. 
large facial nevi, poliosis, and albinism or gray-hued complexions. ${ }^{1}$ These features represent the illustrator's perception of what evil should look like and what the audience should perceive a villainous character to look like, with the goal of invoking fear and apprehension in viewers. Unfortunately, the artistic practice of using certain facial characteristics and skin conditions to represent moral corruption in a character inevitably causes us to project these negative feelings onto individuals in real life with similar characteristics.

Often, exposure to these animated movies begins in childhood, planting the idea very early in life that evil people look a certain way and further perpetuating stigmas. This issue has even prompted the formation of advocacy groups such as NOAH (National Organization for Albinism and Hypopigmentation) to discourage the use of these stereotypes in film. ${ }^{1}$ These principles can be applied not only to the aforementioned facial features, but to nasal characteristics as well. The standards of facial beauty differ by culture and have changed over time. In the past century, mathematicians and plastic surgeons have sought to define ideal facial proportions using geometry and digital analysis. Facial beauty emphasizes certain geometric proportions, angles, and balance. Contours with gentle curves create facial shadows and highlights. The attractive nose is not the focus of attention, but draws attention to the eyes which is the essence of social interaction. A nose perceived as unattractive has the potential to attract negative attention that can alter the perception of an individual and affect their success and interactions in society. ${ }^{2}$ Classic features used to analyze the nose include nasofrontal angle, nasolabial angle, projection, columellar show, and dorsal hump. Evaluating these specific nasal features can give specific illusions and characteristics to a nose. Performing nasal analysis on both animated heroes and villains can define certain nasal features which are specific to a villain or a hero. In this study, nasal features of villains and heroes were analyzed. This study gives insight into what nasal features can potentially put physicians and other health care providers at risk of bias when seeing patients that have these certain nasal qualities.

\section{Methods}

A Google search was performed using the term "top animated villains." Characters were then obtained from American Film Institute's “The Top Tens," Rolling Stone's "25 Best Pixar Movie Characters," and Screenrant's "The 30 Best Animated Movie Characters of All Time." ${ }^{3-5}$ Twenty animated characters were chosen from these lists as well as their 20 counterparts. The characters were subjectively chosen from these lists based on which appeared most humanlike and also had a humanlike counterpart. In total 40 characters were chosen to be evaluated. Selection criteria used in this study included: animated character, villain or hero with a counterpart, and humanlike nasal features. Villains and heroes were excluded based on the following exclusion criteria: nose does not resemble human features or no nose, or no humanlike counterpart.

For each of the 40 characters included, nasal and facial analyses were performed. Large and highly pixelated pictures were chosen of each character from a Google search. The Google Chrome Protractor app was used to measure angles. The following nasal and facial features were evaluated for on all of the characters chosen: presence of a dorsal hump, nasofrontal angle, nasolabial angle, chin projection, columellar show, and lastly descriptions of the nasal features.

The standard measurements, used for comparison, were taken from Powell's proportions of the aesthetic face. These standards included the following: nasolabial angle, 90 to 95 degrees in men and 95 to 110 degrees in women, and the nasofrontal angle, measuring 115 to 130 degrees. The nasolabial angle and nasofrontal angle were measured for each character. Columellar show was subjectively assessed for. The chin was termed overprojected if it protruded further than the nasal tip. The nose was then subjectively assessed for further characteristics, including pollybeak deformity, long, short, pointy, and wide/bulbous tip. These results were collected similarly for both the villains and heroes. A two-sample $t$-test was then performed to compare the results of the villains and heroes. These data were used to look for a statistically significant difference between the mean nasofrontal and nasolabial angle measurements in villains and heroes. The relationship between the type of character and certain nasal features (dorsal hump, columellar show) was assessed using the Fischer's exact test. A $p$-value $<0.05$ was considered to be statistically significant. Statistical analysis was performed using GraphPad Prism (GraphPad Software Inc.).

\section{Results}

Overall, heroes were composed of 12 male and 8 female, and villains were composed of 14 male and 6 female. The mean nasofrontal angle was $147.4 \pm 30.128$ degrees in villains, while it was $158.35 \pm 27.49$ degrees in heroes. There was no significant difference in the nasofrontal angle between villains and heroes $(p=0.24)$. Sixteen villains $(80 \%)$ had greater than normal nasofrontal angles and eighteen heroes (90\%) had greater than normal nasofrontal angles. Thirteen villains (65\%) were found to have an acute nasolabial angle versus two heroes (10\%). The mean nasolabial angle was $81.39 \pm 44.19$ degrees in villains, while it was $126.8 \pm 26.82$ degrees in heroes. There was a significant difference in the nasolabial angle between villains and heroes $(p<0.0003)$. Two villains $(10 \%)$ had columellar show versus seven heroes (35\%). Seven villains (35\%) were found to have a dorsal hump versus one hero (5\%). Being a villain correlated with having a dorsal hump $(p=0.04)$, but not with columellar show $(p>0.05)$. Being a villain was correlated with having an overprojected chin ( $p=0.0095)$. Characteristics most commonly used to describe the villain noses included long (55\%) and pointy (40\%). Characteristics most commonly used to describe the hero noses included small (45\%), short (40\%), and overrotated (40\%). The occurrences of these features in heroes versus villains are displayed in - Fig. 1. A breakdown of specific characters chosen, corresponding movie, and facial analysis of each character are shown in -Tables 1 and 2. In pre-2000s films, villains more frequently had a dorsal hump $(n=7)$, overprojected chin $(n=9)$, ptotic tip $(n=3)$, pollybeak deformity $(n=2)$, or bulbous tip $(n=3)$ when compared with post- 


\section{Nasal descriptions}

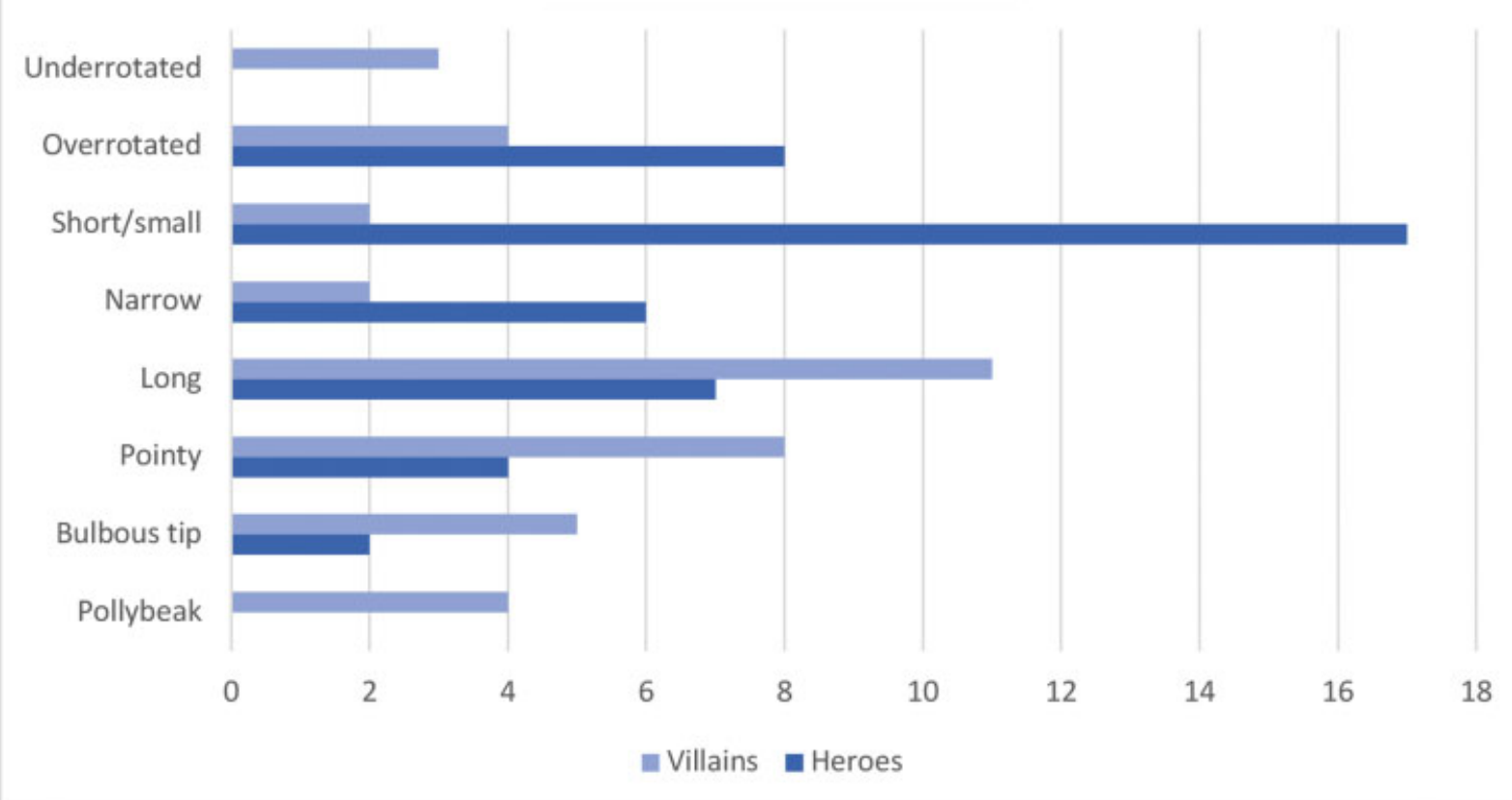

Fig. 1 Nasal description comparisons: heroes versus villains

Table 1 Summary of nasal and facial features of all villains analyzed

\begin{tabular}{|c|c|c|c|c|c|c|c|c|}
\hline Character & Movie & Sex & $\begin{array}{l}\text { Dorsal } \\
\text { hump }\end{array}$ & NF & NL & Chin & $\begin{array}{l}\text { Columellar } \\
\text { show }\end{array}$ & Description \\
\hline Captain Hook & Peter Pan & M & $\mathrm{Y}$ & 134 & 63.7 & OP & None & Underrotated, pollybeak, bulbous tip \\
\hline Jafar & Aladdin & $M$ & $\mathrm{Y}$ & 156 & 30.4 & $\mathrm{OP}$ & None & Underrotated, pollybeak \\
\hline Maleficent & Sleeping Beauty & $\mathrm{F}$ & Y & 134 & 52.3 & $\mathrm{OP}$ & None & Hump, long \\
\hline Lord Farquaad & Shrek & M & $\mathrm{N}$ & 192 & 65.8 & $\mathrm{OP}$ & Yes & Long \\
\hline Gaston & Beauty and the Beast & $\mathrm{M}$ & $\mathrm{Y}$ & 120 & 117 & $\mathrm{OP}$ & None & Overrotated \\
\hline Hades & Hercules & $\mathrm{F}$ & $\mathrm{N}$ & 180 & 25 & $\mathrm{OP}$ & None & Long, pointy \\
\hline Ursula & Little Mermaid & $\mathrm{F}$ & $\mathrm{Y}$ & 127 & 62.6 & $\mathrm{OP}$ & None & Hump, long, pointy \\
\hline Judge Claude & $\begin{array}{l}\text { Hunchback of } \\
\text { Notre Dame }\end{array}$ & M & $\mathrm{Y}$ & 131 & 90 & $\mathrm{IL}$ & None & Long, pointy, pollybeak \\
\hline Clayton & Tarzan & M & $\mathrm{Y}$ & 116 & 44 & OP & Yes & Underrotated, bulbous, pollybeak \\
\hline Evil Queen & Snow White & $\mathrm{F}$ & $\mathrm{N}$ & 150 & 60 & OP & None & Long, curved \\
\hline Sid & Toy Story & $\mathrm{M}$ & $\mathrm{N}$ & 165 & 158 & UP & None & Overrotated, bulbous tip \\
\hline Grimmel & $\begin{array}{l}\text { How To Train } \\
\text { Your Dragon }\end{array}$ & M & $\mathrm{N}$ & 175 & 57 & $\mathrm{OP}$ & None & Long, flat, pointy \\
\hline Mr. Nebbercracker & Monster House & M & $\mathrm{N}$ & 147 & 45 & IL & None & Bulbous tip \\
\hline Chef Skinner & Ratatouille & $\mathrm{M}$ & $\mathrm{N}$ & 148 & 45 & IL & None & Pollybeak, short, bulbous \\
\hline Syndrome & The Incredibles & $\mathrm{M}$ & $\mathrm{N}$ & 170 & 96 & IL & None & Short, pointy, narrow \\
\hline Yzma & Emperor's New Groove & $\mathrm{F}$ & $\mathrm{N}$ & 58 & 164 & IL & None & Overrotated, small, pointy \\
\hline Shan Yu & Mulan & $M$ & $\mathrm{~N}$ & 170 & 60 & OP & None & Long, pointy \\
\hline Disgust & Inside Out & $\mathrm{F}$ & $\mathrm{N}$ & 135 & 168 & IL & None & Overrotated, small, pointy \\
\hline Mor'du & Brave & $M$ & $\mathrm{~N}$ & 176 & 98 & $\mathrm{IL}$ & None & Long, narrow, straight \\
\hline Prince Hans & Frozen & $M$ & $\mathrm{~N}$ & 164 & 126 & $\mathrm{OP}$ & No & Long, narrow, straight \\
\hline
\end{tabular}

Abbreviations: F, female; IL, in line; M, male; NF, nasofrontal angle; NL, nasolabial angle; OP, overprojected; UP, underprojected. 
Table 2 Summary of nasal and facial features of all heroes analyzed

\begin{tabular}{|c|c|c|c|c|c|c|c|c|}
\hline Character & Movie & Sex & $\begin{array}{l}\text { Dorsal } \\
\text { hump }\end{array}$ & $\mathrm{NF}$ & NL & Chin & $\begin{array}{l}\text { Columellar } \\
\text { show }\end{array}$ & Description \\
\hline Peter Pan & Peter Pan & M & $\mathrm{N}$ & 120 & 141 & $\mathrm{IL}$ & Yes & Small, short, overrotated \\
\hline Aladdin & Aladdin & $\mathrm{M}$ & $\mathrm{N}$ & 157 & 150 & IL & None & Long, wide, overrotated \\
\hline Sleeping Beauty & Sleeping Beauty & $\mathrm{F}$ & No & 152 & 150 & IL & Yes & Long, slim, overrotated \\
\hline Shrek & Shrek & $\mathrm{M}$ & No & 180 & 110 & IL & Yes & Wide, flat, large \\
\hline Belle & Beauty and the Beast & $\mathrm{F}$ & No & 145 & 112 & IL & None & Narrow, straight, overrotated \\
\hline Hercules & Hercules & $\mathrm{M}$ & No & 173 & 110 & IL & None & Straight, large \\
\hline Ariel & Little Mermaid & $\mathrm{F}$ & No & 156 & 135 & IL & None & Small, overrotated \\
\hline Quasimodo & Hunchback of Notre Dame & $\mathrm{M}$ & No & 76 & 180 & IL & Yes & Wide, verrotated, bulbous tip \\
\hline Tarzan & Tarzan & M & $\mathrm{N}$ & 158 & 79 & $\mathrm{OP}$ & Yes & Long, narrow, pointy \\
\hline Snow White & Snow White & $\mathrm{F}$ & $\mathrm{N}$ & 145 & 141 & IL & None & Small, short, overrotated \\
\hline Woody & Toy Story & $\mathrm{M}$ & $\mathrm{N}$ & 150 & 105 & IL & None & Long, straight, narrow \\
\hline Hiccup & How To Train Your Dragon & $\mathrm{M}$ & $\mathrm{N}$ & 155 & 128 & $\mathrm{IL}$ & Yes & Overrotated, straight, long \\
\hline DJ & Monster House & M & $\mathrm{N}$ & 151 & 130 & IL & No & Small, short, narrow \\
\hline Alfredo Linguini & Ratatouille & $\mathrm{M}$ & $\mathrm{N}$ & 192 & 120 & UP & Yes & Long, bulbous tip, large \\
\hline Mr. Incredible & The Incredibles & $\mathrm{M}$ & $\mathrm{Y}$ & 210 & 111 & $\mathrm{OP}$ & None & Short, pointy, small \\
\hline Kronk & Emperor's New Groove & $\mathrm{M}$ & $\mathrm{N}$ & 184 & 77 & $\mathrm{OP}$ & None & Long, narrow \\
\hline Mulan & Mulan & $\mathrm{F}$ & $\mathrm{N}$ & 175 & 101 & IL & None & Short, small \\
\hline Joy & Inside Out & $\mathrm{F}$ & $\mathrm{N}$ & 168 & 160 & IL & None & Overrotated, short, small \\
\hline Merida & Brave & $\mathrm{F}$ & $\mathrm{N}$ & 155 & 160 & IL & None & Short, small pointy \\
\hline Elsa & Frozen & $\mathrm{F}$ & $\mathrm{N}$ & 165 & 136 & IL & None & Short, small, pointy \\
\hline
\end{tabular}

Abbreviations: F, female; IL, in line; M, male; NF, nasofrontal angle; NL, nasolabial angle; OP, overprojected; UP, underprojected.

Table 3 Comparison of villainous features between pre- and post-2000s films

\begin{tabular}{|l|l|l|}
\hline Nasal feature & Pre-2000 films & Post-2000 films \\
\hline Dorsal hump & 7 & 0 \\
\hline Overprojected chin & 9 & 3 \\
\hline Ptotic tip & 3 & 0 \\
\hline Pollybeak deformity & 2 & 1 \\
\hline Bulbous tip & 7 & 1 \\
\hline
\end{tabular}

2000s films ( $n=0,3,0,1,1$, respectively). Comparisons of villainous nasal features between pre- and post-2000s films are depicted in - Table 3. Hero nasal feature have stayed more consistent over the years with the exception of a more frequent overrotated tip in pre-2000s films $(n=7)$ versus post-2000s films $(n=2)$.

\section{Discussion}

\section{Nasal Characteristics}

Multiple nasal characteristics were analyzed in this study. Definitions of each characteristic and ideal measurement ranges for these were obtained from Frankel and Mehta's "Nasal Analysis." ${ }^{6}$ The nasofrontal angle is the angle between a line tangent to the nasal dorsum and a line tangent to the glabella through the nasion, which should be 115 to 135 degrees. Any measurement larger than this gives the individual the look of a long nose from the frontal view. From the results in this study, there was no statistically significant difference in the nasofrontal angle between heroes and villains. The nasolabial angle is formed by a line from the subnasale to the most anterior point of the columella and a line connecting to the labrale superius to the subnasale, which should be between 90 and 95 degrees in men and 95 and 110 degrees in women. The larger the nasolabial angle, the more overrotated the nasal tip, and the more of an individual's nostrils the observer is able to see when they are at the eye level with that individual. The smaller the nasolabial angle, the more underrotated the nasal tip. This study found there to be a statistically significant difference in the nasolabial angle between villains and heroes. Therefore, an underrotated, or ptotic, nose is considered a characteristic of a villainous nose. Nasal and chin projections should ideally be equal, with a vertical line able to be drawn from the nasal tip directly to the chin. The nose can appear overprojected or underprojected if not directly in line with the chin. The ideal nasal projection is typically thought of as a 3:4:5 right triangle on profile view. An enlarged nasal dorsum, known as a dorsal hump, is one of the most common reasons for rhinoplasty and gives the appearance of a "bump" on the top of the nose and the look of an overall larger nose on side profile. According to this study, being a villain was correlated with a dorsal hump. A 
pollybeak deformity is similar to a dorsal hump, but the hump is located in the supratip region. This causes the tip to be pushed downward and creates an underrotated nasal tip, and this was also more commonly found in a villain nose.

\section{Nasal Design in the Animation of Movie Villains and Heroes}

Because the length of a movie is limited, a character on screen has to have a look that is distinct enough to allow the viewer to come to conclusions about the character and develop emotional attachment to them fairly quickly. Villains in movies typically have less screen time than heroes; therefore, they have even less time to develop their character and back story and allow the audience to appreciate their complexity. Since first impressions are generated so easily, the most efficient way to do this is via the character's visual appearance. Most heroes are designed more around oval shapes, which is often seen as friendly and safe, similar to a baby. ${ }^{7}$ Our analysis supported this idea and showed that hero noses were commonly described as small or short, as opposed to villain noses that were commonly described as long and pointy. Angular shapes are seen as more dangerous, so animators use triangles and pointy shapes in villains. ${ }^{7}$ Oftentimes a 45-degree angle is used to do this, including in the eyebrows, cheekbones, jawbones, ears, and hair because the slant is seen and feared by humans in animal predators in nature. ${ }^{8}$ We saw this in our nasal analysis when we discovered that many animated villain noses have an acute nasolabial angle, creating that menacing and primal 45-degree angle. Although the nose is just one aspect of someone's appearance, villain faces often make use of Freud's idea of the "uncanny" in which something is familiar but a little bit off, just enough to make one do a double-take. ${ }^{8}$ Therefore, the nose is often used in these characters to give that "uncanny" and unsettling nature to our favorite villains.

Interestingly, in films made prior to the year 2000 (Snow White, Peter Pan, Sleeping Beauty, The Little Mermaid, Beauty and the Beast, Aladdin, Toy Story, The Hunchback of Notre Dame, Hercules, Mulan, and Tarzan), villains more frequently had a dorsal hump, overprojected chin, ptotic tip, pollybeak deformity, or bulbous tip when compared with villains in films after the year 2000 (The Emperor's New Groove, Shrek, The Incredibles, Monster House, Ratatouille, How to Train Your Dragon, Brave, Frozen, and Inside Out). Hero nasal features have stayed more consistent over the years with the exception of a more frequent overrotated tip in pre-2000s films versus post-2000s films. The majority of the films prior to the year 2000 were by Disney, and the majority from the year 2000 and beyond were by Pixar. It is possible that these changes in classic features over time could be due to both differences between studios and production companies, and to advancements in animation technology allowing illustrators to make animated noses even more human-like, detailed, and refined. The differences between pre- and post-2000 nasal features could also represent a changing social climate and demographic makeup of the United States. Prior to the year 2000, heroes were classically depicted with a historically European small, "upturned" nose, and villainous characters were depicted with traditionally non-European stereotypical nasal features to depict them as "other." In a publication by Villanueva et al, the features classically seen in different ethnicities and how they affect rhinoplasty evaluation are described. ${ }^{9}$ This study reports that a Caucasian nose is likely to be equally proportioned, symmetric, and have a smooth dorsum, whereas noses from individuals of other ethnicities are more likely to have features such as a bulbous tip or dorsal hump. With the United States becoming more diverse in recent decades, these previously stereotypical villainous features may be seen as less "other" because they are much more common in everyday society, and the stereotypical European upturned nose is becoming less of a majority. The change between what were previously considered villainous and heroic nasal features compared with recent decades is reflected in our data showing that dorsal hump, overprojected chin, ptotic tip, pollybeak deformity, or bulbous tip in a villain are far less frequently used after the year 2000 , and the upturned/overrotated nose has become less frequent in heroes in post-2000s films.

\section{Implications of Nasal Features as a Depiction of Evil}

After completing nasal analysis on animated heroes versus villains, it is shown that both have very distinct nasal characteristics. This allows the viewer to differentiate them from each other and determine whether they are good or evil without ever having to see, hear, or know anything else about the character. This can have large implications on human interaction in the society. The importance of facial appearance has been shown to influence the assignment of positive attributes and even employment decisions. ${ }^{10}$ In addition, the viewer of a film, as well as individuals in real life, have been found to make first impressions in just 7 to 12 seconds. ${ }^{11}$ Humans make automatic and sometimes unconscious judgments about an individual based on something as simple as facial and body shapes, which are heavily used in animation as a character design technique. ${ }^{12}$ The visual appearance of an individual provides an instant way for the observer to come to conclusions about that person's role, personality, and belief system.

It is also a common belief in our society that humans attribute positive character traits to individuals typically thought of as "attractive." Aesthetically the nose should fit harmoniously with face, allowing the attention to be focused on the eyes. Features such as a ptotic tip and dorsal hump are characterized as unattractive and draw the viewers' attention toward the nose. Interestingly, our data demonstrate that villain noses more commonly include these features when compared with their hero counterparts. Some of the most common rhinoplasty procedures for nasal cosmesis involve dorsal hump reduction, tip reduction, and tip rotation. ${ }^{2} \mathrm{~A}$ study by Kandathil et al reports that when both dorsal hump reduction and tip rotation simulations were used on patient images, the person was found to be more attractive and healthier. ${ }^{2}$ In addition, in a study by Nellis et al it was reported that patients benefit from rhinoplasty not only by improving casual observers' perceptions of attractiveness, but also perceptions of success and overall health. ${ }^{10}$ Similarly to these 
studies describing the effect of rhinoplasty on societal perceptions of an individual, Ishii et al have published extensive work on how facial defects, expression, and asymmetry also affect facial perception. ${ }^{10,13-16}$ One study describes how observers allocated attention differently when gazing at faces with a crooked nose compared with those without by changing their gaze pattern to focus more attention on the nose. Although our study did not contain characters with asymmetric noses, this idea could also be true for those with villainous nasal features. ${ }^{16}$ Another study reported that when an observer allocates attention to a discriminating feature, they gain information about the identity and emotional state of the individual, and this behavior is conserved between age, race, and gender. ${ }^{13}$ The present study proposes a possible reason for why the studies by Nellis et al and Kandathil et al, ${ }^{2,10}$ along with the extensive work on facial perception done by Ishii et $\mathrm{al}^{10,13-16}$ have found such significant effects on societal interactions and perception of an individual based on one's facial characteristics.

Animated movies often appeal to children, and are integrated into everyday life at an early age. Evolutionarily, we inherited the perception of oval shapes as safe and soft, and angular shapes as a warning for possible danger. ${ }^{7}$ It is no surprise as to why animators often use these techniques in their design choices. Similar to Pavlov's dog, seeing a character with classic villainous features repeatedly on screen early in life can prime thoughts of a villainous human. Unfortunately, this can lead to associations not only based on nasal features, but also with race and ethnicity as well. ${ }^{17}$ From a medical perspective, it is up to physicians and other health care providers to recognize these inherent biases and not let that color first judgments of patients. This may also help provide insights into some of the psychological stressors rhinoplasty patients are dealing with, as the incidence of body dysmorphic disorder is higher in this population compared with others seeking cosmetic surgery.

\section{Conclusion}

Our analysis demonstrated that animated villains more commonly have an acute nasolabial angle leading to an underrotated ptotic tip, overprojected chin, dorsal hump, and pollybeak deformity when compared with animated movie heroes. Animated movie heroes were found to more commonly have a large nasolabial angle leading to an overrotated tip, as well as an in-line chin when compared with their villain counterparts. Further research in conjunction with psychologists is required to obtain concrete data on how this affects human perception on whether an individual in real life is seen as good or evil and how that affects interactions in the society, including in the medical field.
Conflict of Interest

None declared.

\section{References}

1 Croley JA, Reese V, Wagner RF Jr. Dermatologic features of classic movie villains: the face of evil. JAMA Dermatol 2017;153(06): 559-564

2 Kandathil CK, Saltychev M, Moubayed SP, Most SP. Association of dorsal reduction and tip rotation with social perception. JAMA Facial Plast Surg 2018;20(05):362-366

3 American Film Institute. AFI's 100 years...100 heroes \& villains. Available at: https://www.afi.com/afis-100-years-100-heroesvillians/. Accessed June 27, 2020

4 Rolling Stone. 25 Best pixar movie characters. Available at: https://www.rollingstone.com/movies/movie-lists/25-best-pixar -movie-characters-164982/violet-parr-the-incredibles-2004-16 4040/. Accessed July 26, 2020

5 ScreenRant. The 30 best animated movie characters of all time. Available at: https://screenrant.com/best-animated-movie-characters/. Accessed July 26, 2020

6 Frankel AS, Mehta U. Nasal Analysis. In: Azizzadeh B, ed. Master Techniques in Rhinoplasty. Amsterdam: Elsevier Inc.; 2011:31-42

7 Graphic mama. How to convey character's personality through shape variance and size. Available at: https://graphicmama.com/blog/conveying-characters-personality/. Accessed June 27, 2020

8 WSJ. What makes an actor look like a bad guy? Available at: https://www.wsj.com/articles/the-secret-to-looking-sinister-on -screen-1502118703. Accessed June 27, 2020

9 Villanueva NL, Afrooz PN, Carboy JA, Rohrich RJ. Nasal analysis: considerations for ethnic variation. Plast Reconstr Surg 2019;143 (06):1179e-1188e

10 Nellis JC, Ishii M, Bater KL, et al. Association of rhinoplasty with perceived attractiveness, success, and overall health. JAMA Facial Plast Surg 2018;20(02):97-102

11 Dream Farm Studios. Psychological insights on character design. Available at: https://dreamfarmstudios.com/blog/character-animation-studio/. Accessed June 27, 2020

12 Nieminen M. Psychology in character design: creation of a character design tool. 2017. Available at: https://www.theseus.fi/bitstream/ handle/10024/126784/MarikaNieminen_Thesis.pdf?sequence $=1 \&$ isAllowed $=\mathrm{y}$. Accessed August 24, 2020

13 Ishii L, Carey J, Byrne P, Zee DS, Ishii M. Measuring attentional bias to peripheral facial deformities. Laryngoscope 2009;119(03): 459-465

14 Ishii LE, Nellis JC, Boahene KD, Byrne P, Ishii M. The importance and psychology of facial expression. Otolaryngol Clin North Am 2018;51(06):1011-1017

15 Dey JK, Ishii M, Boahene KDO, Byrne P, Ishii LE. Impact of facial defect reconstruction on attractiveness and negative facial perception. Laryngoscope 2015;125(06):1316-1321

16 Roxbury C, Ishii M, Godoy A, et al. Impact of crooked nose rhinoplasty on observer perceptions of attractiveness. Laryngoscope 2012;122(04):773-778

17 CNN. Doctors take a hard look at movie villains, warts and all. . Available at: https://www.cnn.com/2017/04/05/health/movievillains-skin-dermatology-study/index.html. Accessed June 27, 2020

Financial Disclosures

None 